\title{
Em busca de uma avaliação mais "justa"
}

\section{Resumo}

O exame ou prova se configura no principal instrumento avaliativo utilizado por professores de matemática. Tal instrumento está enraizado em nossa cultura educacional, sendo concebido a partir de uma filosofia positivista que atesta um caráter imparcial, neutro e justo à avaliação escolar. No entanto, estudos relacionados a docimologia fornecem resultados que contestam tal senso de justiça. Este artigo apresenta alguns resultados de uma pesquisa de multicorreção realizada com licenciandos em matemática e, posteriormente, professores formados e atuantes. Os resultados obtidos revelaram o caráter subjetivo da correção de provas discursivas de matemática. Primeiramente, forneceram indícios da existência do efeito halo, em que a ordem das questões a serem corrigidas influenciaria o resultado da correção. Posteriormente, a subjetividade foi evidenciada pela grande amplitude de notas atribuídas a uma mesma prova tanto por licenciandos, com uma variação de " 4,5 pontos", quanto por professores, quando a amplitude de notas atribuídas teve uma oscilação de "3,5 pontos". Também são discutidas tentativas de obter critérios para a correção de questões abertas em avaliações em larga escala, que garantam a equidade dos códigos atribuídos. A partir da análise desses e de outros resultados, e dialogando com renomados pesquisadores da área, esse artigo problematiza a crença na justiça das avaliações escolares em matemática e traz algumas reflexões pertinentes sobre o tema para pesquisadores, professores e futuros professores de matemática.

Palavras-chave: avaliação escolar; avaliação em matemática; subjetividade na avaliação; multicorreção. 


\title{
In search of a more "fair" evaluation
}

\author{
Rafael Filipe Novôa Vaz \\ Lilian Nasser
}

\section{Abstract}

The examination or test figures as the main instrument of assessment used by mathematics teachers. Such instrument is rooted in our educational culture, being conceived from a positivist philosophy that certifies an impartial, neutral and reliable character to school evaluation. However, studies related to the docimology supply results that contest such sense of justice. This article presents some results of a research of multicorrection carried through with undergraduate mathematics students and, later, with mathematics active teachers. The results obtained have disclosed the subjective character of the correction of discursive mathematics tests. First, they gave indications of the existence of the halo effect, where the order of the questions to be corrected would influence the result of the correction. Later, the subjectivity was evidenced by the great amplitude of the attributed marks given to the same test, both by undergraduate future teachers, with a variation of " 4,5 points", as by teachers, when the amplitude of attributed marks had a variation of " 3,5 points". Furthermore, attempts to get criteria for the correction of open questions on large scale evaluations are argued in order to guarantee the equity of attributed codes. From the analysis of these and other results, and dialoguing with famous researchers of the area, this article discusses the belief in the justice of school evaluations in mathematics and brings some pertinent reflections on the subject for researchers, professors and future mathematics teachers.

Key words: assessment; assessment in mathematics; subjectivity in assessment; multicorrection. 


\section{Introdução}

Reconhece-se hoje que o ensino da Matemática não pode limitar-se apenas à transmissão de conceitos matemáticos, pois é necessário que os alunos desenvolvam competências que lhes permitam lidar com situações e problemas que envolvem diferentes formas de pensamento em diferentes contextos. De modo análogo, a avaliação escolar em Matemática não pode resumir-se à aplicação de um exame. A avaliação escolar como concebemos hoje surgiu por volta do século XVII e, talvez, não seja mais tão adequada para mensurar essas competências e habilidades. A própria ideia de que é possível medir a aprendizagem de um indivíduo pode ser questionada.

Para Perrenoud (1999), a avaliação tornou-se indissociável da escola quando se inicia o ensino de massa no século XIX. Desde então, as concepções pedagógicas da avaliação escolar sofreram algumas mudanças. No entanto, a literatura aponta que estas mudanças conceituais ligadas às ciências da educação devem ser acompanhadas por transformações na prática avaliativa em sala de aula (JORBA; SANMARTÍ, 1993; PERRENOUD, 1999; FERNANDES, 2009; PINTO, 2011). Cada vez mais,

considera-se que se você quiser mudar a prática educativa é necessário promover a mudança nas práticas avaliativas, isto é, a sua finalidade, o que é avaliado e como ocorre a avaliação. Em países como a Inglaterra e Israel, as mudanças no currículo - na seleção de conteúdos e a metodologia utilizada pelos professores na de sala de aula - foram mais motivadas por alterações instituídas em testes externos aplicados aos estudantes, do que pela definição de novos programas e novos rumos para o planejamento atividades de ensinoaprendizagem. (JORBA; SANMARTÍ, 1993, p.20; tradução nossa)

Perrenoud (1999) escreveu, há cerca de 20 anos, que a avaliação era tradicionalmente associada, na escola, à criação de hierarquias de excelência, pois os alunos são comparados e depois classificados. Apesar de todos os avanços tecnológicos relacionados, principalmente, à internet e às telecomunicações, pouca coisa mudou na dinâmica das aulas: os quadros negros foram substituídos pelos quadros brancos e, posteriormente, pelos slides, mas a aula continua sendo essencialmente expositiva. De modo análogo, mesmo com os avanços nas teorias do ensino e da aprendizagem, a avaliação escolar continua amparada em uma filosofia positivista, com a predominância de exames para 'medir' a aprendizagem dos estudantes. (GUBA; LINCOLN, 2011). Em relação a situação brasileira,

geralmente quando se fala em Avaliação Educacional, o que vem à mente é a concepção de rendimento escolar, ou de desempenho, confundida com a ideia de medida pontual. Não sem razão, visto que esta é a modalidade de avaliação mais presente no cotidiano das pessoas. Como nossas escolas emergiram sob a égide da preparação de elites, a avaliação seletiva no cotidiano escolar firmou-se, por centenas de anos, como cultura preponderante. (GATTI, 2002, p. 17) 
Em 2008, a Unesco alertou para a necessidade de construção de uma escola para todos, com características inclusivas e sustentáveis, reafirmando a necessidade de igualdade de acesso à aprendizagem. Essa perspectiva traz à escola novos desafios e novas missões que implicam na reestruturação das culturas, das políticas e das práticas pedagógicas. Trata-se de uma mudança complexa, pois ideias inclusivas não dialogam facilmente com as concepções meritocráticas enraizadas no meio escolar. Especificamente, em relação à avaliação escolar, "associar o mérito de forma linear à obtenção de bons resultados de aprendizagem, para além de ser um embuste, não ajuda a repensar como é que a escola pode ajudar os estudantes que trabalham e se esforçam, mas não alcançam o resultado desejado.” (PINTO, 2011, p. 54-55).

Os exames escolares possuíam, e ainda possuem, as seguintes características: são individuais, escritos, sem consulta, com tempo delimitado, esporádicos, intermitentes e breves, possibilitam a ausência de convivência como exigência para avaliar, oferecem tratamento genérico a todos os alunos com a pretensão de serem neutros (RAPHAEL, 1998). Esse modelo avaliativo é fundamentado na visão positivista, que tem seus pilares na neutralidade e imparcialidade. (MORGAN, 2000; GUBA; LINCOLN, 2011). Tais concepções estão presentes nos três pressupostos básicos que sustentam o pensamento geral na avaliação:

primeiro, presume-se que os indivíduos possuem atributos (como conhecimento, compreensão, habilidade, etc.) que são detectáveis e mensuráveis. Em segundo lugar, o objetivo principal da avaliação é descobrir e medir esses atributos. Finalmente, o processo de avaliação e seus resultados são considerados fundamentalmente benignos ou mesmo benéficos (embora efeitos colaterais infelizes possam ser reconhecidos e tentativas feitas para melhorá-los) (MORGAN, 2000, p. 225-226, tradução nossa).

Essa visão positivista tem sido confrontada com outra, baseada no construtivismo, o que dá origem a uma nova concepção de avaliação. Este artigo pretende discutir a filosofia positivista que embasa as concepções avaliativas, apresentar os possíveis vieses cometidos na correção de provas e caminhos para evitar esses vieses. A partir do modo como os professores elaboram e corrigem os instrumentos de avaliação de seus alunos, são apresentadas algumas propostas que podem direcionar os professores na construção de uma avaliação mais justa.

\section{Entre dois paradigmas}

Alguns pesquisadores identificaram a existência de uma tensão na avaliação escolar (PERRENOUD, 1999; MORGAN, 2000; ROMAGNANO, 2001; HADJI, 2001; FERNANDES, 2009; GUBA; LINCOLN, 2011). De um lado a concepção positivista, relacionada à seleção e classificação, adequada a alguns sistemas escolares. De outro, "uma pedagogia diferenciada, com uma maior individualização das trajetórias” (PERRENOUD, 1999, p.10) que preconiza a integração, amparada em uma "maior afirmação de pressupostos ontológicos, epistemológicos 
e metodológicos menos subordinados ao positivismo" (FERNANDES, 2009, p. 26).

Em uma abordagem mais ampla de avaliação, Guba e Lincoln (2011) defendem a ruptura das concepções positivistas em prol das construtivistas. Segundo esses autores, o modelo convencional de avaliação em que o avaliador detém "poder e autoridade de tomada de decisões, não é apenas moral e eticamente injusto e equivocado; ele é também politicamente ingênuo e conceitualmente limitado" (p.21). Na concepção construtivista, a verdade é uma construção fundamentada e as constatações de uma investigação são influenciadas pelo próprio processo investigativo, ou seja, diversos fatores externos e internos, como a interferência do professor, por exemplo, podem alterar o resultado da avaliação escolar. As avaliações, do jeito como são concebidas, provavelmente perdem seu atual significado a partir dessa ruptura.

A necessidade de mudanças nas concepções e práticas avaliativas também é defendida por Fernandes (2009), que aponta três razões para tal:

(i) Evolução das teorias da aprendizagem. Os testes ou exames aplicados há cerca de 100 anos atrás eram centrados na memorização, com fortes características behavioristas. Na época, havia um senso comum de que a aprendizagem ocorria pela acumulação de pequenos elementos de conhecimento, havia um isomorfismo entre os testes e a aprendizagem, os testes deveriam ser utilizados para garantir o domínio dos assuntos, antes de progredir para um outro, pois a aprendizagem se dava em uma perspectiva linear e hierárquica. A partir do momento em que a aprendizagem passa a ser vista como um processo ativo de construção mental, que o que se aprende é determinado social e culturalmente, que as interações sociais apoiam o desenvolvimento das competências cognitivas, que as novas aprendizagens são determinadas pelos conhecimentos prévios e que a metacognição, o autocontrole e a autorregulação das competências são indispensáveis para o desenvolvimento do estudante, os testes, da maneira que eram interpretados, tornaram-se ultrapassados;

(ii) Desenvolvimento das teorias do currículo. Nos últimos 30 anos as sociedades tornaram-se mais multiculturais, mais competitivas e muito mais exigentes. Nesse contexto, os currículos de hoje lançam desafios que vão muito além da memorização. A ideia parece ser a de procurar garantir que os sistemas educacionais preparem jovens capazes de lidar com situações complexas, de resolver problemas em contextos diversificados nacionais e internacionais, de trabalhar em grupos cada vez mais multiculturais, de se comunicar facilmente em sua língua e, pelo menos, em uma língua estrangeira, de saber utilizar as novas tecnologias da informação, de ser tolerantes com as diferenças, de ser cidadãos críticos e participativos na vida democrática das sociedades. (FERNANDES, 2009, p. 36) 
Citando Shepard (2000, 2001), Fernandes (2009) considera que os desenvolvimentos curriculares dos últimos vinte anos estão contribuindo para a substituição do Currículo da Eficiência Social por uma Visão Reformada do Currículo, inspirada segundo os autores, em visões construtivistas, socioculturais e cognitivistas das aprendizagens. Segundo Fernandes (2009), o Currículo da Eficiência Social foi predominante no mundo ocidental durante todo o século XX, começando a ser questionado, somente, nos anos 70 e 80, possuindo as seguintes características: distribuição de alunos por turmas, de acordo com as competências que revelam, definição exaustiva de objetivos comportamentais e a utilização sistemática de testes objetivos para medir a aprendizagem. Por essa concepção, somente uma minoria poderia avançar ao nível superior, pois a capacidade de aprender conhecimentos científicos e acadêmicos era um dom restrito a poucos estudantes. A Visão Reformada do Currículo orienta que todos os alunos podem aprender, que os conteúdos devem desafiar os alunos em processos complexos de pensamento, que todos devem ter acesso à oportunidade de aprendizagem, que os alunos devem ser incentivados a adotar hábitos de reflexão e atitudes favoráveis à aprendizagem em uma perspectiva democrática e inclusiva.

(iii) Democratização dos Sistemas Educativos. Fernandes (2009, p. 39) afirma que "o acesso de todas as crianças e jovens ao bem da educação é conquista das sociedades democráticas”. Segundo este autor, as avaliações podem motivar ou desestimular a aprendizagem dos estudantes, podem construir alavancas para o aprendizado ou funcionar como barreiras para o desenvolvimento escolar. A avaliação pode segregar ou integrar. Logo, as avaliações devem ser planejadas para orientar os estudantes acerca dos saberes, das capacidades e das atitudes que eles têm que desenvolver, para influenciar na motivação e percepção do que é importante aprender, melhorar e consolidar as aprendizagens, para promover o desenvolvimento dos processos de análise, síntese e reflexão crítica e para desenvolver os processos metacognitivos, o autocontrole e a autorregulação.

Guba e Lincoln (2011) defendem que as avaliações, elaboradas e conduzidas no paradigma científico ou positivista, parece gerar uma exagerada dependência em relação à mensuração quantitativa formal. Contrariando as concepções relacionadas a esse paradigma, Hadji (2001) afirma que o julgamento do avaliador é "sempre infiltrado por elementos provenientes do contexto escolar e social" e, geralmente, "ignora que se baseia em parte em uma representação construída do aluno e em convicções íntimas que nada tem de científicas" (p.32). Para esse autor, a avaliação não é uma medida, porque "o avaliador não é um instrumento e porque o que é avaliado não é um objeto no sentido imediato” (p.34).

Buriasco e colaboradores defendem que a avaliação é composta por um mito e um rito, em que, via de regra, "negligencia-se que o quantitativo advém do qualitativo", sendo produzida por um avaliador que utiliza instrumentos para efetuar uma medida. Deste modo, 
"o rito de avaliar se constitui numa prática que confere uma validade ilusória ao mito da possibilidade do exercício da precisão e da justiça”. (BURIASCO; FERREIRA; CIANI, 2009, p.72).

Fischer (2008) realizou uma pesquisa com professores universitários que atuam em cursos de licenciatura afim de investigar suas concepções em relação à avaliação. Nesse trabalho foi constatado que os professores formadores associam a objetividade na avaliação escolar à clareza, à uniformidade nos critérios de avaliação e à neutralidade no campo da matemática. A autora cita a fala ambígua de um professor que diz privilegiar "a exatidão do conteúdo, mas valoriza, na correção, o desenvolvimento apresentado pelo aluno” (p.85). Para a autora, talvez seja mais difícil para o professor de matemática, devido a sua formação, compreender a subjetividade existente na avaliação escolar.

Refiro-me à avaliação como um possível outro território, em que nós, professores de matemática, estaríamos exercendo um discurso coagente, um discurso que não permite dubiedade ou recusa. (...). Mesmo que o ensino de matemática possa ter-se edificado nessas bases, de verdades absolutas e inquestionáveis, a relação entre professor e aluno, nos processos de ensino e de aprendizagem e, particularmente, no que diz respeito à avaliação, não é matematizável. (FISCHER, 2008, p.95-96)

Segundo Romagnano (2001), a decisão dos professores de incorporar algumas dessas técnicas de avaliação menos familiares é frequentemente interpretada no meio escolar como uma troca da objetividade pela subjetividade. Pois, segundo esse pesquisador, na concepção dos professores,

os métodos tradicionais de avaliação, que às vezes são estreitamente focados em habilidades e procedimentos, são pelo menos medidas objetivas dessas habilidades e procedimentos. Por outro lado, abordagens alternativas - que têm o potencial de avaliar a compreensão conceitual dos alunos e sua capacidade de resolver problemas e raciocinar - são, infelizmente, subjetivas. (ROMAGNANO, 2001, p. 31, tradução nossa)

No entanto, para Romagnano (2001, p.31) a objetividade seria como um "mítico pote de ouro no final do arco-íris, seria maravilhoso se pudéssemos tê-lo, mas ele não existe. Todas as avaliações da compreensão matemática dos alunos são subjetivas”. Pacheco (1998) questiona a neutralidade da prova escrita e atribui a essa forma avaliativa um caráter intrinsicamente subjetivo, relacionado à correção. Para o autor, a nota do aluno é o resultado da relatividade de um juízo e que é delimitado tanto por fatores de ordem pessoal, psicológica e social como por fatores curriculares.

Os estudos docimológicos, ligados à experiência de multicorreção, têm demonstrado as divergências de notação quando um mesmo corretor, com algum intervalo de tempo, atribui 
resultados diferentes a um teste (PACHECO, 1998). A próxima sessão apresenta e discute resultados mais recentes de uma pesquisa em multicorreção.

\section{A pesquisa em multicorreção e o paradigma positivista}

Esta investigação faz parte de um estudo de multicorreção em provas de matemática, que se iniciou em 2017, com licenciandos em Matemática, e, atualmente, investiga professores formados e atuantes. No decorrer desse estudo diversos resultados forneceram subsídios para o questionamento das concepções positivistas da avaliação escolar. A seguir serão apresentados os principais resultados dessa pesquisa.

\section{Efeito Halo}

O efeito halo consiste no julgamento do todo a partir de características obtidas inicialmente e, se apresenta quando uma impressão é formada a partir de uma característica inicial influenciando múltiplos julgamentos ou classificações de fatores não relacionados. $\mathrm{O}$ efeito halo induziria o professor a corrigir de modo distinto as provas de seus alunos a partir das respostas às primeiras questões, ou seja, se o efeito halo for constatado, as resoluções das questões iniciais dos estudantes influenciarão o corretor durante a correção das questões seguintes.

Segundo Kahneman (2012), caso as primeiras soluções de uma prova dissertativa estivessem corretas (ou com uma pontuação alta), o professor tenderia a corrigir esta prova com maior propensão a atribuir boas pontuações nas questões seguintes, provocando um efeito halo na avaliação escolar. Assim, quanto maior for a pontuação das questões iniciais, mais provável será a atribuição de melhores pontuações nas questões seguintes, e consequentemente, maior será a nota da prova. Kahneman (2012) descreve o efeito halo em sua prática avaliativa do seguinte modo:

No início da minha carreira como professor, eu dava as notas para as provas dissertativas de meus alunos do modo convencional. Eu pegava um caderno de cada vez e lia todas as respostas daquele aluno em imediata sucessão, dando notas à medida que prosseguia. [...]. Comecei a desconfiar que meu sistema de notas exibia o efeito halo, e que cada pergunta avaliada por mim tinha um efeito desproporcional na nota geral. (KAHNEMAN, 2012, p.108)

As primeiras investigações (Fase 1) foram realizadas com cerca de 40 alunos da Licenciatura em Matemática do IFRJ, uma instituição pública, federal, localizada no interior do estado do Rio de Janeiro, sobre a ocorrência do efeito halo na correção de provas. Os estudantes foram divididos em dois grupos: A e B. Cada aluno corrigiu uma prova contendo 4 questões discursivas sobre a resolução de equações do $2^{\circ}$ grau e atribuiu uma nota de o a 10. $\mathrm{O}$ valor de cada questão foi estipulado em 2,5, ficando a cargo de cada corretor atribuir outros ISSN 2526-2882 
valores a respostas parcialmente corretas. Havia uma diferença entre o ordenamento das questões contidas nas duas provas: no teste A, a primeira questão continha uma solução correta enquanto que a última apresentava uma solução incorreta. No teste $\mathrm{B}$, questões e soluções eram reposicionadas na ordem inversa, para verificar se os licenciandos atribuiriam notas semelhantes às provas dos tipos A e B (figura 1). Em ambos os testes, as questões intermediárias apresentavam resoluções parcialmente corretas, de acordo, é claro, com o julgamento dos pesquisadores.

Figura 1 - Testes A e B da fase 1.

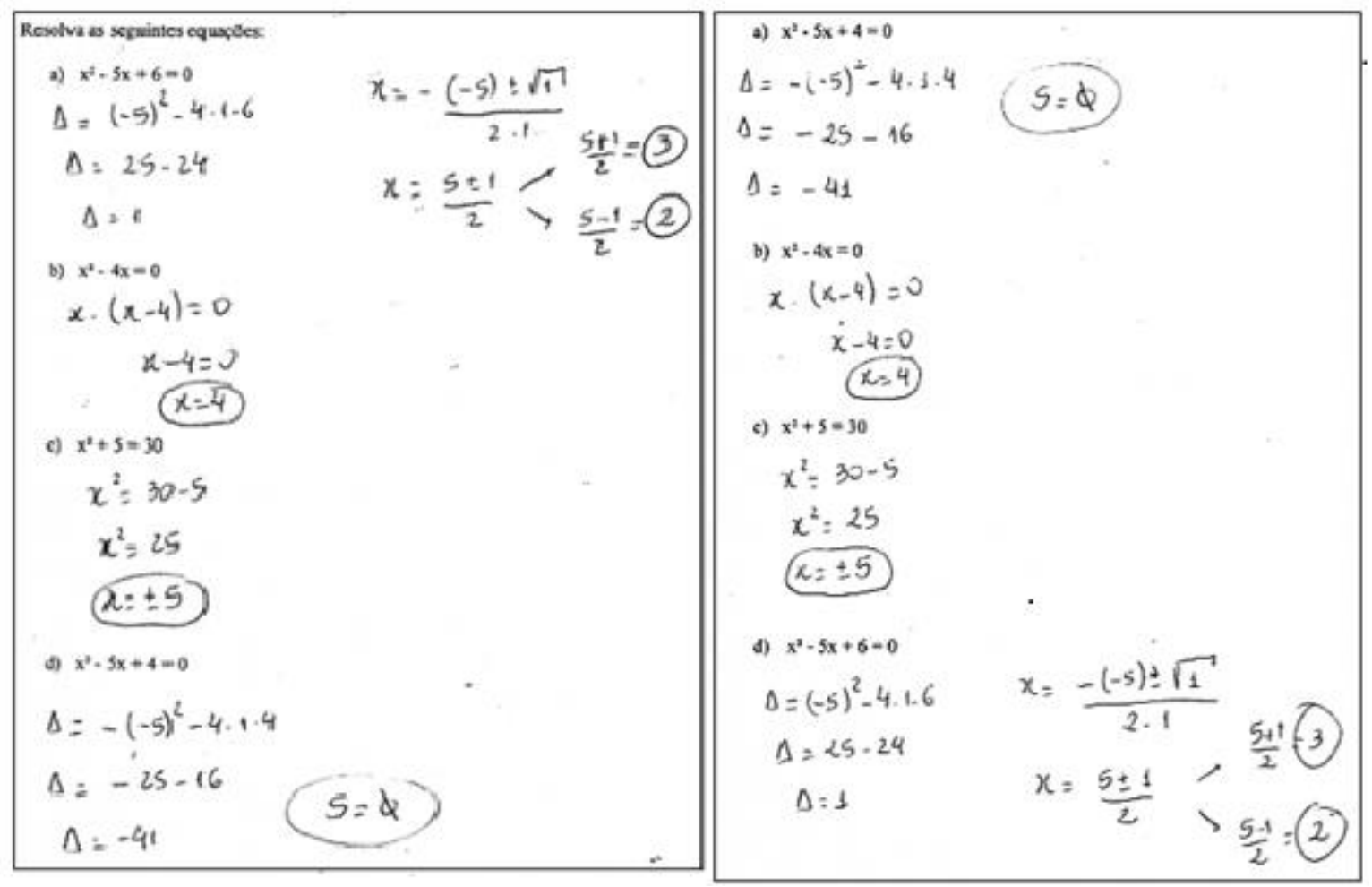

Fonte: VAZ; NASSER (2018a)

Nesse estudo, os resultados dos testes A e B indicaram a existência do efeito halo, pois a média, a moda e a mediana das notas foram menores no teste A quando comparados ao teste B. A conclusão desta fase é que, possivelmente, os futuros professores tentaram realizar uma compensação ao corrigir o teste $\mathrm{B}$, em que a solução da primeira questão estava incorreta, sendo mais benevolentes ao atribuir notas às questões seguintes. (VAZ; NASSER, 2018a)

Tabela 1 - Média, moda e mediana, fase 1

\begin{tabular}{|c|c|c|}
\hline & Teste A & Teste B \\
\hline Média & 6,43 & 7,17 \\
\hline Moda & 6,25 & 7,25 \\
\hline Mediana & 6,5 & 7,25 \\
\hline
\end{tabular}

Fonte: VAZ; NASSER (2018a)

ISSN 2526-2882 
Utilizando o erro padrão, foi estimado um intervalo de confiança para a média populacional a partir da média amostral calculada, com um nível de significância de $5 \%$, ou seja, este intervalo de confiança tem $95 \%$ de probabilidade de conter a média real de notas referentes aos dois testes.

Tabela 2 - Intervalo de confiança, fase 1

\begin{tabular}{|c|c|}
\hline Teste A & Teste B \\
\hline$[6,2 ; 6,7]$ & {$[7,1 ; 7,3]$} \\
\hline
\end{tabular}

Fonte: VAZ; NASSER (2018a)

As tabelas 1 e 2 apresentam indícios de que o efeito halo pode realmente ocorrer na correção de provas, principalmente quando o docente corrige prova por prova. No entanto os resultados deste estudo divergiram dos previstos por Kahneman (2012), pois a questão errada posicionada no início da prova (teste B) gerou notas maiores.

Dependendo das concepções do docente sobre educação e sobre a própria matemática, haverá uma tendência de desvalorização ou de valorização das questões posteriores a partir do resultado das soluções iniciais. Docentes com características mais inclusivas tenderiam a corrigir de modo mais benéfico uma prova caso a primeira questão apresentasse uma resposta incorreta, por outro lado, docentes menos preocupados com a inclusão, que creem que uma correção mais rigorosa será benéfica ao estudante, tenderiam a corrigir as questões seguintes da mesma prova atribuindo uma pontuação menor. Possivelmente pelo fato de os licenciandos da instituição investigada possuírem características mais inclusivas, observou-se que a pontuação média do teste $\mathrm{B}$ foi maior que a do teste $\mathrm{A}$.

\section{A amplitude de notas}

Na etapa seguinte, Fase 2, investigou-se a presença do efeito halo na correção de provas com questões discursivas com características mais argumentativas, cujas respostas pressupõem uma maior interpretação dos respondentes. Foi utilizada outra amostra, desta vez, de 45 licenciandos, em matemática, pertencentes a dois campi do IFRJ. De modo análogo à primeira fase da investigação, os testes foram aplicados em duas versões X e Y, distribuídos de modo arbitrário entre dois grupos de licenciandos, a partir do seu posicionamento na sala. A figura 1 ilustra um exemplo do teste X. A primeira questão apresentava uma solução correta, a quinta questão apresentava uma solução totalmente incorreta e as três questões intermediárias (2, 3 e 4) apresentavam questões parcialmente corretas. No teste $Y$, as mesmas questões e resoluções eram apresentadas invertendo a ordem das questões e suas respectivas soluções. (VAZ; NASSER, 2018b) 
Figura 2 - Teste $\mathrm{X}$ das fases 2 e 3 .

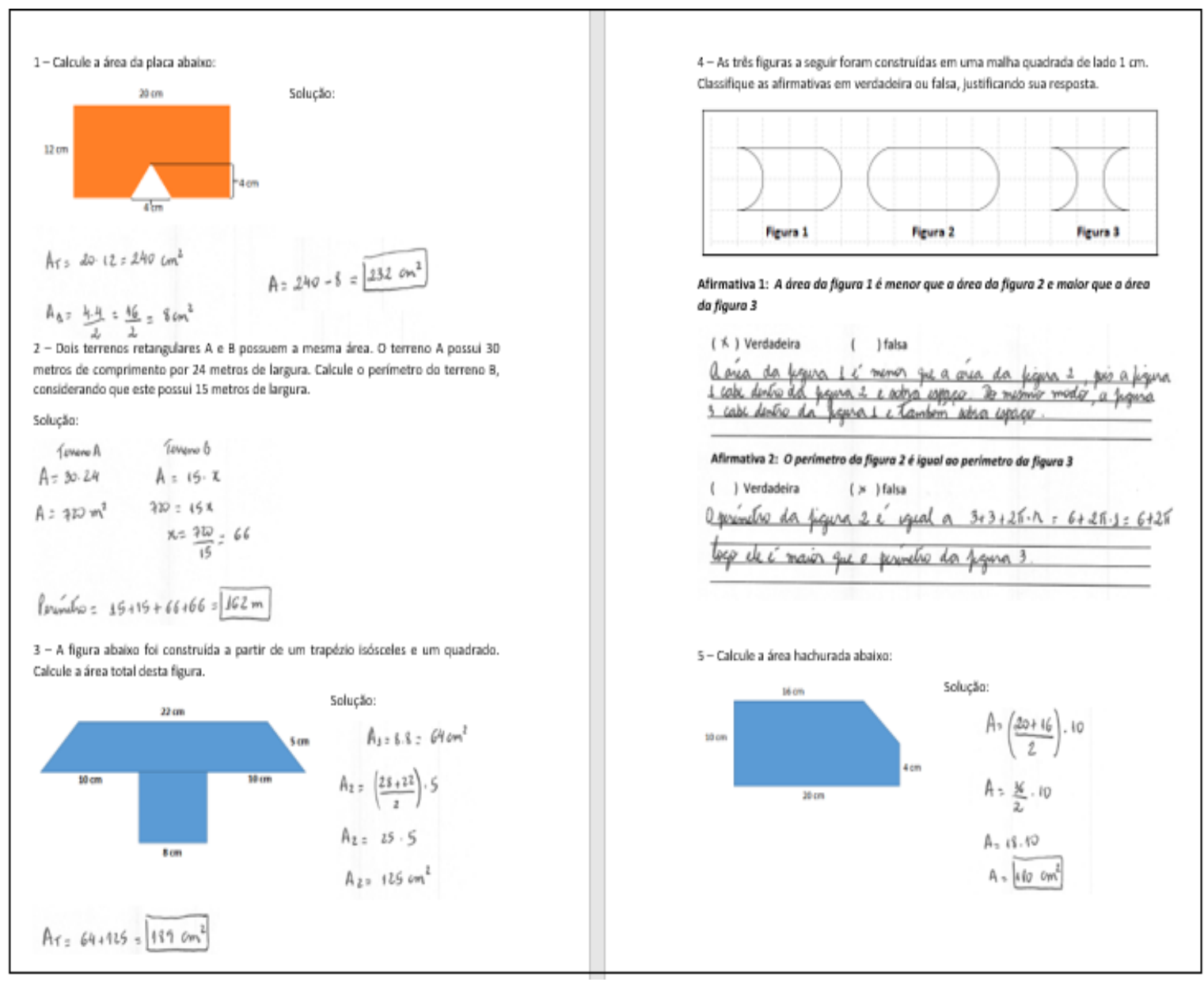

Fonte: VAZ; NASSER (2018b)

Os resultados desta etapa, diferentemente da primeira fase, não indicaram a presença do efeito halo na correção das provas. A tabela 3 indica que, sob as mesmas condições da primeira fase (nível de confiança de $95 \%$ e de significância 5\%), os novos dados geram intervalos de confiança com um grande intervalo de interseção, não sendo constatada diferença significativa entre as médias.

Tabela 3 - Intervalo de confiança, fase 2

\begin{tabular}{|c|c|}
\hline Teste $\mathrm{X}$ & Teste $\mathrm{Y}$ \\
\hline$[3,76 ; 4,98]$ & {$[4,03 ; 5,21]$} \\
\hline \multicolumn{2}{|c|}{ Fonte: VAZ; NASSER $(2018 \mathrm{~b})$} \\
\hline
\end{tabular}

A partir desses resultados, duas hipóteses podem ser levantadas para justificar a não ocorrência do efeito halo: A primeira seria que durante a correção da fase 2 os licenciandos utilizaram uma maior concentração para corrigir as questões da prova devido a sua característica argumentativa, o que proporcionaria uma menor subjetividade na correção. A 
segunda está relaciona ao público, o segundo campus envolvido na pesquisa talvez contenha licenciandos menos preocupados com a inclusão, o que equilibraria o resultado. Novos estudos poderiam, e deveriam, ser realizados sobre a ocorrência do efeito halo.

No entanto, foi constatada uma grande amplitude das notas atribuídas, fator que merece ser estudado. Contrariando a concepção de prova como uma medida, os resultados foram bem distintos dentre os corretores, como mostra o gráfico 1.

Gráfico 1 - Frequência de notas, fase 2

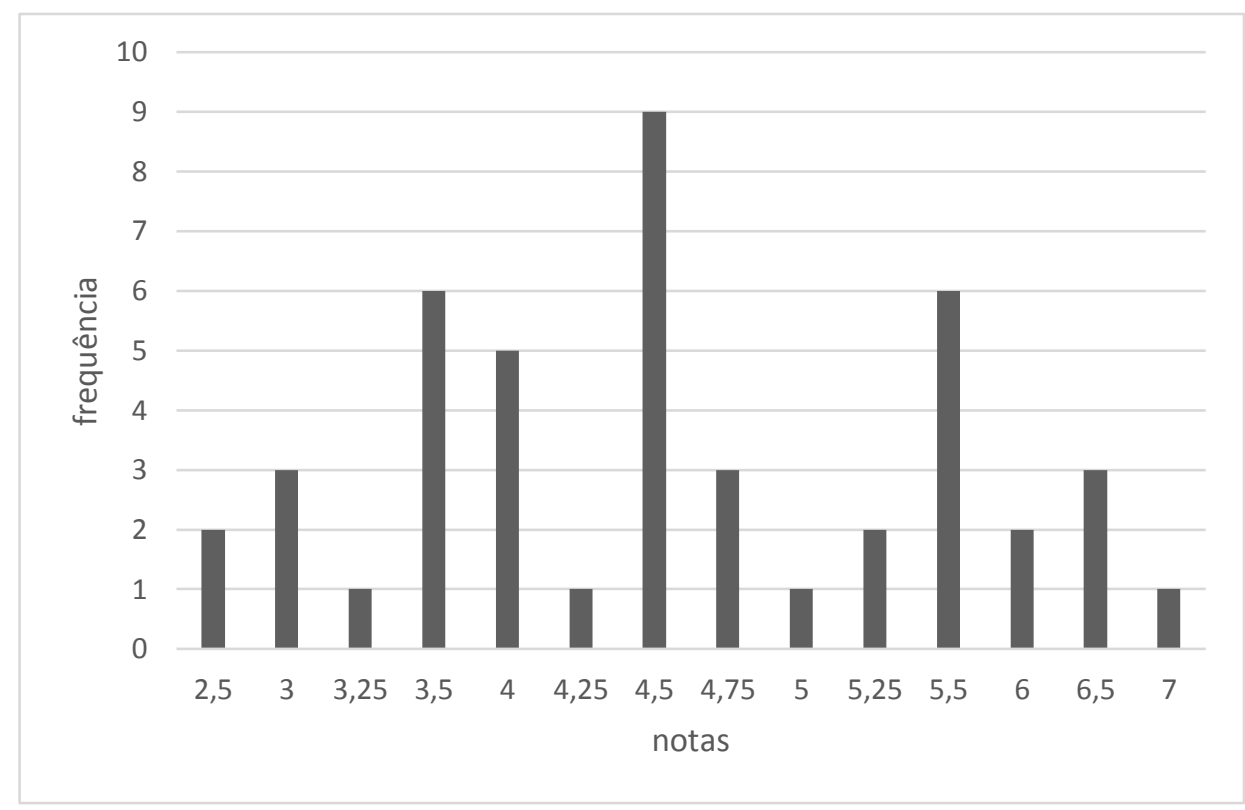

Fonte: VAZ; NASSER (2018b)

Como uma mesma prova (de um estudante fictício), com o mesmo gabarito e sendo atribuída a mesma pontuação por questão pode gerar resultados tão distintos? A resposta mais plausível a essa pergunta é a subjetividade dos corretores. A prova é uma leitura, não uma medida, e como toda leitura, pode ser interpretada de modo distinto a partir das crenças e concepções do leitor. Nesse estudo,

a média das notas obtidas é 4,54 e o intervalo de confiança com (nível de confiança de $95 \%$ é $[4,22 ; 4,86]$. Note que há uma probabilidade de $95 \%$ de que a "média desta prova" - supondo que a nota seja uma medida - pertença a esse intervalo. Isto significa dizer que 17 corretores atribuíram uma nota menor ao intervalo de confiança (nota $<4,22$ ) e que 15 corretores atribuíram uma nota superior a ele (nota $>4,86$ ). Além disso, apenas, 13 corretores atribuíram uma nota no intervalo estatisticamente determinado pela média. (VAZ; NASSER, 2018b, p. 5-6)

Em uma terceira fase da pesquisa, a investigação foi realizada com professores de matemática do Projeto Fundão/UFRJ. Foi solicitado a 14 professores que participam desse projeto de extensão que corrigissem o mesmo teste da fase 2, em uma única sequência (por se ISSN 2526-2882 
tratar de uma amostra pequena, optou-se em não investigar o efeito halo). Todos os professores que participaram da pesquisa são formados e atuantes, e considerando que participam de um grupo colaborativo, a expectativa era que a amplitude das notas fosse reduzida.

De fato, os resultados indicaram a redução, no entanto, ela foi menor que o esperado. Como pode ser observado na fase 2, as notas oscilaram entre 2,5 e 7,0, com uma variação de “4,5 pontos”. Já com os professores, a oscilação foi de “3,5 pontos”, de 4,0 a 7,5, de acordo com a distribuição das notas mostrada no gráfico 2.

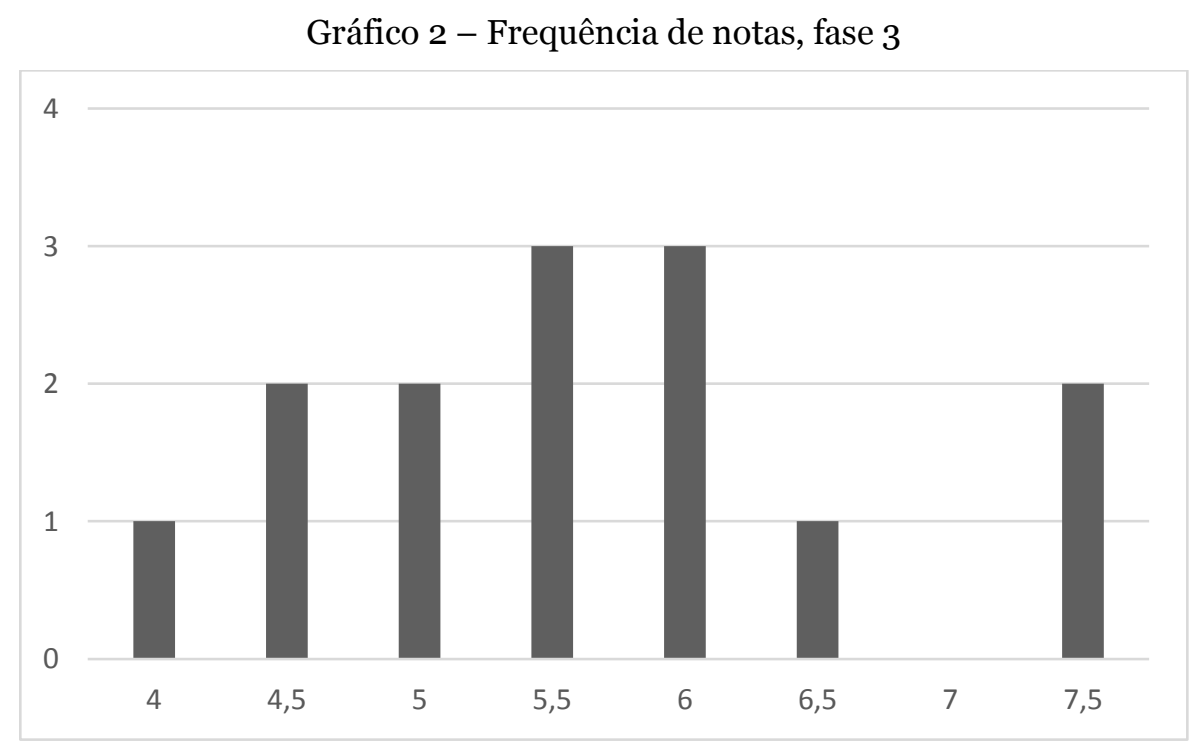

Fonte: VAZ; NASSER (2019)

Considere uma escola que exige 6,o como a nota mínima de seus estudantes para a aprovação. Aprova resolvida pelo fictício estudante o habilitaria à aprovação na concepção de 6 professores, entretanto, para os outros 8 docentes, a mesma prova poderia conduzir o estudante a uma possível retenção. Ou seja, a aprovação do estudante não estaria condicionada exclusivamente à sua aprendizagem, e sim aos critérios do professor que corrigisse sua prova.

Mesmo considerando a hipótese que o conhecimento de alguém possa ser mensurado, que os professores sejam absolutamente neutros em sua atuação profissional e que todos os testes fossem construídos com embasamento científico com neutralidade e objetividade, a crença na possibilidade de usar o teste para "medir" de alguma forma o conhecimento também é questionada a partir desses resultados. (VAZ, NASSER, 2019, p. 7)

Tais resultados entram em consonância com os estudos de Morgan e Watson (2002). Estas autoras realizaram uma pesquisa em que foi constatado que os professores têm ideias diferentes acerca do modo como os alunos devem ser avaliados. As variações, segundo estas 
autoras, são influenciadas também pelas expectativas culturais. Segundo essas autoras, a "incompatibilidades entre os recursos culturais e linguísticos de professores e alunos", por exemplo, "ocasionam processos avaliativos prejudiciais os alunos de grupos sociais não dominantes" (p. 103). Nas avaliações em que os alunos têm a oportunidade de responder às tarefas de avaliação de maneiras abertas, a confiabilidade pode ser um objetivo impossível (MORGAN; WATSON, 2002)

A seguir, são apresentados resultados que confirmam a dificuldade de confiar nos resultados de avaliações de resposta aberta.

\section{Diversidade de critérios e concepções de corretores}

Uma das questões propostas para a correção nas fases 2 e 3 da pesquisa ( $2^{\mathrm{a}}$ questão do teste $\mathrm{X}$, mostrado na figura 2) apresentava a solução de um estudante fictício, do nono ano do ensino fundamental, que comete um erro ao realizar uma divisão na segunda parte da solução de uma questão. A figura 3 ilustra a correção de dois professores na fase 3.

Figura 3 - Comparativo de correção

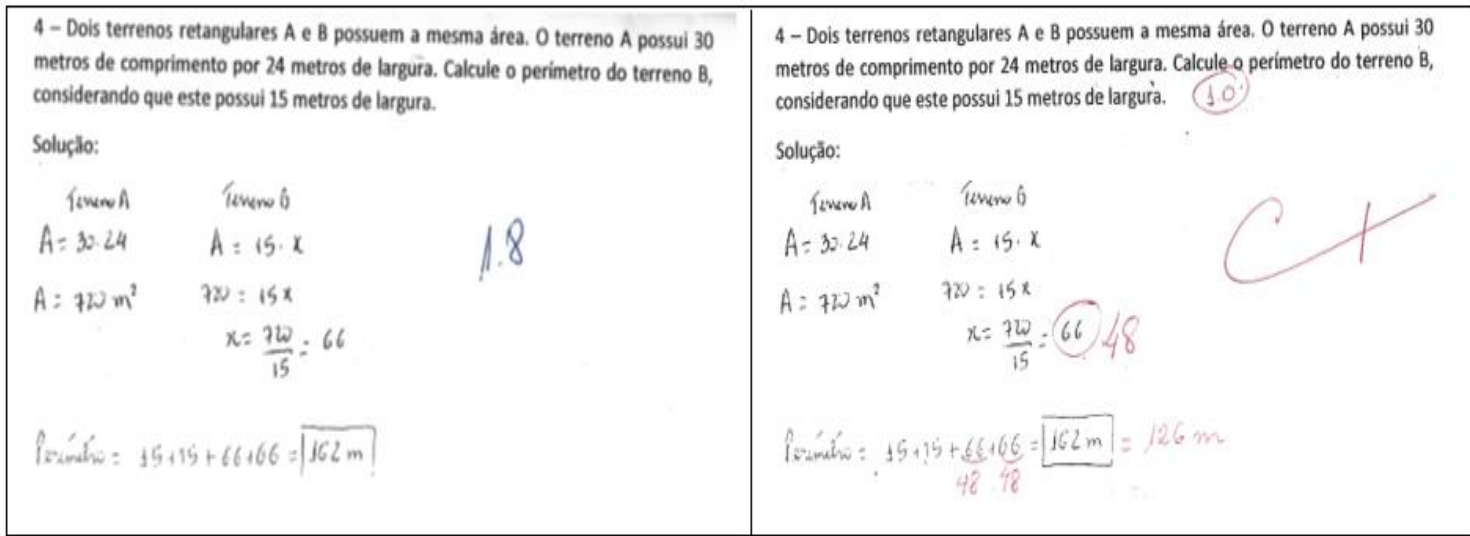

Fonte: VAZ; NASSER (2019)

As pontuações apresentadas na figura 3 foram acompanhadas por outros três docentes, no caso de 1,o ponto, e outros dois, no caso da pontuação de 1,8. Observe que a solução apresentada contém 3 partes, em sequência: cálculo da área do terreno A, cálculo da medida do comprimento do terreno B e o cálculo do perímetro. Note que há um erro deste estudante na segunda parte (erro na divisão) e que o procedimento utilizado na terceira parte é o correto, mas utiliza valores errados, oriundos da parte anterior, para o cálculo do perímetro.

Uma hipótese para a atribuição de pontuações tão distintas está relacionada a como os professores interpretam a última parte dessa solução, para alguns (que atribuíram nota 1,0) a ênfase está no resultado, para outros (que atribuíram nota 1,8) a ênfase está no processo. Essa problemática pode ocorrer com frequência numa questão com itens (a) e (b), por exemplo, ISSN 2526-2882 
quando estes são dependentes, ou seja, para resolver o item (b) se utiliza o resultado do item(a). Os critérios utilizados pelos professores são diferenciados e, possivelmente, influenciados pela maneira como os docentes interpretam os erros dos seus estudantes e da forma como concebem a Matemática. Deste modo, uma sugestão deste estudo é que os professores evitem utilizar em suas avaliações itens ou questões dependentes.

Os resultados obtidos oferecem indícios do forte impacto subjetivo da correção de provas de matemática. O efeito Halo, a amplitude de notas e as características interpretativas da correção das provas trazem um alerta para o grande potencial de desigualdade e de injustiça das avaliações. Segundo Morgan e Watson (2002, p. 103), essa "desigualdade seria uma consequência necessária da natureza interpretativa da avaliação que ocorre na interação humana”.

Faz parte do ofício do estudante, de acordo com Perrenoud (1999, p. 45), “aprender a apresentar um trabalho, a fazer linhas e margens nos cadernos e folhas, a pôr títulos, seu nome, data, a apresentar um texto, a identificar perguntas e comentários, exemplos, indicação sobre o valor deste ou daquele exercício", resolver exames e participar de outros processos avaliativos. De modo análogo, faz parte do ofício do professor apresentar e explicar o conteúdo, resolver exercícios, tirar dúvidas, avaliar as aprendizagens dos estudantes e, mais especificamente, elaborar, aplicar, corrigir e atribuir notas a um trabalho ou exame. A partir dessas informações, surgem algumas perguntas:

- Quais critérios o professor utiliza para a correção de um exame com questões discursivas?

- Os estudantes conhecem os critérios adotados pelo professor na avaliação?

- O que importa, ou deveria importar na correção de testes, é o resultado final ou o desenvolvimento?

- Um erro de conta tem o mesmo peso que um erro de conceito?

Diversas perguntas emergem, e poderão emergir, na reflexão sobre a avaliação das aprendizagens. Se a objetividade pode ser questionada nas avaliações elaboradas e aplicadas pelos professores regentes, será que um questionamento similar poderá ser realizado nas avaliações em larga escala?

\section{O caso das avaliações em larga escala}

As avaliações em larga escala são utilizadas para comparar sistemas de ensino ou para aferir a aprendizagem de um grande número de alunos. O instrumento mais usado nesses casos é uma prova objetiva, com questões de múltipla escolha. Sem dúvida, tal tipo de avaliação não dá margem a discrepâncias entre avaliadores, gerando resultados confiáveis em relação à correção e à conversão do número de acertos em uma nota. 
No entanto, questões de múltipla escolha não são de simples elaboração, e nem sempre refletem o real conhecimento dos alunos. Como não é possível deixar a resposta em branco, e nem aparece uma opção de "nenhuma das respostas anteriores", a alternativa escolhida pode refletir uma resposta aleatória. Como consequência, o professor não tem certeza do conhecimento do aluno, ou seja, mesmo sendo confiável em termos de pontuação, os exames de múltipla escolha podem não refletir exatamente a aprendizagem dos estudantes. Métodos atuais de construção e análise dos resultados, como a Teoria da Resposta ao Item (KLEIN, 1999), permitem chegar a conclusões importantes acerca do desempenho dos estudantes, e, consequentemente, a elaboração de uma escala de proficiência (KLEIN; FONTANIVE, 2009) na tentativa de proporcionar uma análise mais significativa da avaliação.

Outro ponto a discutir é a inadequação de itens de múltipla escolha na avaliação de alguns tipos de habilidades, como elaborar cálculo mental, organizar dados em gráficos ou tabelas, entre outros. Além disso, mesmo que o aluno opte pela alternativa correta, não é possível identificar as estratégias usadas na resolução do problema.

Algumas políticas de avaliação optam por incluir em seus instrumentos problemas de resposta construída, em que é possível distinguir a habilidade dos estudantes em sua resolução, assim como as estratégias utilizadas. Mas a correção desses itens não pode ser feita pelo computador, demandando a análise de um professor. Para garantir a equidade nos resultados, sistemas de avaliação aplicados pelo INEP, como o PISA (Programa Internacional de Avaliação de Estudantes), o ENADE (Exame Nacional de Desempenho dos Estudantes) e o ERCE (Estudo Regional Comparativo e Explicativo) promovem a "codificação" dos itens. Ou seja, em vez de ser corrigida, cada resposta é associada a um código. Além de códigos distintos para respostas em branco e erradas, pode haver diversos códigos de crédito completo, dependendo da estratégia utilizada e também diversos códigos de crédito parcial, dependendo do erro cometido. Para garantir a codificação mais adequada, cada resposta é corrigida por dois avaliadores, e se houver discrepância entre os códigos, o desempate é feito por um terceiro avaliador. Esse processo permite aplicar uma avaliação em larga escala mais justa, com clareza a respeito dos conhecimentos dos estudantes testados.

No entanto, nesse tipo de avaliação as provas e os critérios de codificação são elaborados por um corpo de especialistas. Algumas dessas avaliações são testadas com uma amostra da população para avaliar a adequação das questões e os critérios de codificação. Os dados dessa amostra são corrigidos por um grupo de profissionais treinados. E, mesmo assim, geralmente ocorrem discrepâncias entre os corretores, numa pequena porcentagem. Tal fato permite supor que a busca pela objetividade não é alcançada, pelo menos de forma absoluta, mesmo em situações favoráveis como a que parece ocorrer em avaliações de larga escala. 


\section{Algumas contribuições para a construção de uma avaliação "justa"}

Os resultados desta pesquisa estão em consonância com os estudos de (PACHECO, 1998; MORGAN, 2000; HADJI, 2001; GATTI, 2002; FISCHER, 2008; BURIASCO; FERREIRA; CIANI, 2009; FERNANDES, 2009) que apontam a necessidade de romper a visão positivista que associa a prova a um instrumento de aferição da aprendizagem. A ideia de associar a nota de um teste a uma medição é, definitivamente, um mito. "O teste está muito mais próximo de uma leitura do que de uma medida. Uma leitura da aprendizagem e do ensino, que fornece várias interpretações, várias notas" (VAZ; NASSER, 2019, p. 8).

Reconhecendo a existência de um processo dinâmico entre o ensino e a aprendizagem ao longo do tempo, o ensinado hoje pode ser compreendido posteriormente, em outra semana, mês ou ano. Considerando que a aprendizagem não ocorre de forma linear, e sim, através de múltiplas variáveis e muitos fatores que transitam no cognitivo, afetivo e sociocultural, uma pergunta poderia ser formulada: haveria um modo para realizar uma avaliação mais justa? A justiça aqui não está associada à igualdade de direitos e deveres, que a avaliação tradicionalmente costuma contemplar, mas à equidade de oportunidades que permitiria a cada estudante desenvolver, dentro de sua individualidade, melhor suas habilidades e potencialidades. A justiça poderia ser ilustrada pela icônica imagem (figura 4) que circula nas redes sociais.

Figura 4 - Igualdade x Equidade

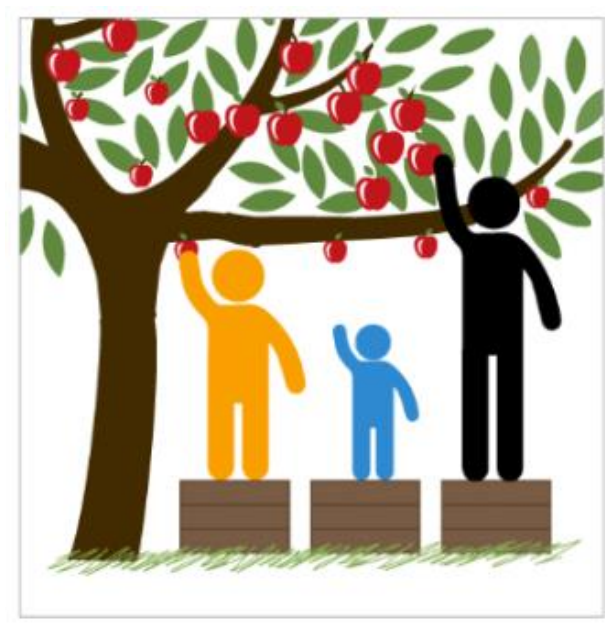

IGUALDADE

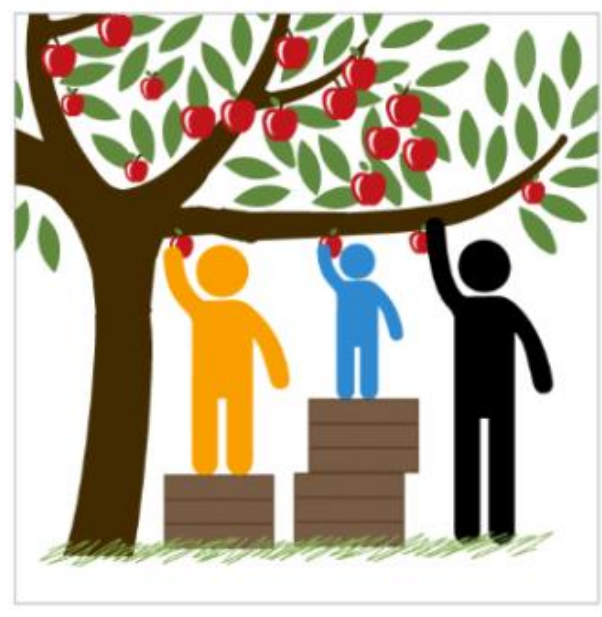

EQUIDADE

Fonte: autor desconhecido

Considerando, os resultados deste trabalho e a bibliografia consultada, é possível apontar caminhos para a ressignificação da avaliação escolar em busca de uma avaliação mais "justa” em sala de aula, descritos a seguir. 


\section{i) Da elaboração e correção dos exames}

É recomendável que o professor estabeleça objetivos bem definidos dos itens elaborados. A validade de uma avaliação depende, também, da coerência existente entre as questões e o que o que se pretende avaliar com elas. Uma questão do tipo 'efetue ou calcule', por exemplo, não será capaz de avaliar a capacidade dos estudantes na 'resolução de problemas' e avaliará habilidades distintas de uma questão do tipo 'análise, demonstre ou identifique o erro'.

Desde a elaboração do item, os critérios de correção devem ser previamente definidos pelo professor. Na construção desses critérios o docente deve estar atento às possíveis respostas dos estudantes, e dispostos, caso necessário, a reconstruir esses critérios. Tais critérios devem dialogar com os objetivos das questões. Se a questão tem como objetivo avaliar o pensamento matemático e elaboração de estratégias para resolver um problema, o desenvolvimento deve ser mais relevante na correção que o resultado final.

Um dos possíveis modos de minimizar a influência do efeito halo é corrigir as provas por itens, ou seja, de um maço de provas, o professor corrige primeiro todas as questões iniciais. Em seguida, na ordem inversa, corrige as questões de número 2, em seguida as terceiras questões, e assim, sucessivamente.

\section{ii) Transparência de critérios de correção}

De acordo com Fernandes (2009), a maioria dos professores não explicita os critérios de avaliação aos estudantes. Em um período letivo, estudantes fazem dezenas de avaliações elaboradas por diversos de professores, que utilizam critérios distintos. Os estudantes têm o direito de conhecer e reconhecer os critérios avaliativos de seus professores antes da aplicação da avaliação para serem capazes de corresponder as expectativas de seus professores na resolução das questões.

Em uma visão mais democrática, esses critérios podem ser construídos na coletividade, com o corpo docente e discente da escola. Os professores não devem, necessariamente, utilizar os mesmos critérios, mas eles devem ser conhecidos pelos estudantes.

\section{iii) Dupla Diversificação}

A avaliação deve ser um processo contínuo e heterogêneo, diversificado em relação aos momentos e aos instrumentos utilizados. A avaliação está mais próxima de um filme do que de uma foto. A avaliação escolar não deve ser restrita aos exames esporádicos em momentos específicos (normalmente nos finais de ciclos) nem, tão pouco, utilizando apenas um instrumento avaliativo, que pode beneficiar alguns grupos em detrimento de outros. "A 
diversidade de métodos de coleta de informações permite avaliar mais domínios do currículo, lidar melhor com a grande diversidade de alunos que hoje estão nas salas de aula e também reduzir os erros inerentes à avaliação" (FERNANDES, 2009, p. 95).

\title{
iv) O abandono da ideia de medida
}

Como dito anteriormente, os exames não devem ser interpretados como uma medida, "avaliar é muito mais que medir" (GATTI, 2002, p. 3). Se o conhecimento é multifacetado, complexo, construído individualmente e inextricavelmente ligado ao contexto no qual o aprendizado ocorre, conclui-se que nenhum instrumento único é capaz de "medir" esse conhecimento de maneira consistente e significativa (ROMAGNANO, 2011).

\begin{abstract}
A interpretação é uma característica essencial da atividade de avaliação e não pode ser eliminada. No entanto, o insight sobre os detalhes de como as diferenças na interpretação ocorrem pode permitir que os professores se engajem na reflexão crítica sobre sua prática e, através dessa consciência crítica, diminua a probabilidade de desigualdade resultante (MORGAN; WATSON, 2002, p. 103, tradução nossa).
\end{abstract}

Desta forma, a avaliação escolar pode ser compreendida como uma leitura que não somente fornece informações da aprendizagem dos estudantes, mas também fornece informações do ensino oferecido pelo professor e pela escola. Ao avaliar o estudante, professor também está sendo avaliado.

Enfim, é preciso reconhecer as limitações e a complexidade do tema. Neste sentido, cabe ressaltar que, como faz parte do ofício do magistério elaborar, aplicar, corrigir e gerar uma nota ou conceito da aprendizagem do estudante, a avaliação escolar deveria receber maior atenção na formação de professores, desde os currículos das licenciaturas até as capacitações iniciais e continuadas de professores.

A avaliação não é neutra, nem tão pouco, imparcial. Como toda a atividade escolar, a avaliação é uma ação humana. É necessário reconhecer a falibilidade dos instrumentos e métodos adotados e rever nossos paradigmas. A partir daí, experimentar novas estratégias avaliativas em busca de uma avaliação mais justa.

\section{Referências}

BURIASCO, R. L. C.; FERREIRA, P. E. A.; CIANI, A. B. Avaliação como prática de investigação: alguns apontamentos. Boletim de Educação Matemática, Rio Claro, v. 22, n. 33, p.69-96. 2009.

FERNANDES, D. Avaliar para aprender: fundamentos, práticas e políticas. São Paulo: Editora Unesp, 2009.

FISCHER, M. C. B. Os formadores de professores de matemática e suas práticas avaliativas. ISSN 2526-2882 
In: VALENTE, W. R. (Org.). Avaliação em matemática: história e perspectivas atuais. Campinas: Papirus, 2008. p. 75 -100.

GATTI, B. A. Avaliação educacional no Brasil: pontuando uma história de ações. EccoS Revista Científica, São Paulo, v. 4, n. 1, p. 17-41, jun. 2002.

GUBA, E. G.; LINCOLN, Y. S. Avaliação de quarta geração. Campinas: Editora da Unicamp, 2011.

HADJI, C. Avaliação desmistificada. Porto Alegre: Artmed Editora, 2001.

JORBA, J.; SANMARTÍ, N. La función pedagógica de la evaluación. Aula de innovación educativa, v. 20, p. 20-30. 1993.

KAHNEMAN, D. Rápido e devagar: duas formas de pensar. Rio de Janeiro: Objetiva, 2012.

KLEIN, R. Métodos estatísticos para avaliação educacional: teoria da resposta ao item. Boletim da ABE, n. 43, p. 21-28. 1999.

KLEIN, R.; FONTANIVE, N. S. Alguns Indicadores Educacionais de Qualidade no Brasil de Hoje. São Paulo em Perspectiva (Impresso), São Paulo, v. 23, p. 19-28. 2009.

MORGAN, C. Better assessment in mathematics education? A social perspective. In: BOALER, J. (Org.). Multiple Perspectives on Mathematics Teaching and Learning. Westport, Ablex Publishing, 2000.p. 225-242.

MORGAN, C.; WATSON, A. The interpretative Nature of Teachers' Assessment of Students' Mathematics: Issues for Equity. Journal for Research in Mathematics Education. v. 33, n.2, p. 78-110. 2002.

PACHECO, J. A. A avaliação da aprendizagem. In: ALMEIDA, L. S.; TAVARES, J. (Org.). Conhecer, aprender, avaliar. Porto: Porto Editora, 1998. p.111-132.

PINTO, J. Percursos escolares e avaliação numa escola inclusiva. In: FERNANDES, D. (Org). Avaliação em educação: olhares sobre uma prática social incontornável. Pinhais: Editora Melo, 2011. p. 53-76.

PERRENOUD, P. Avaliação: da excelência à regulação das aprendizagens - entre duas lógicas. Porto Alegre: Artes Médicas Sul, 1999.

RAPHAEL, H. S. Avaliação escolar: em busca de sua compreensão. São Paulo: Brasiliense, 1998.

ROMAGnANO, L. The myth of objectivity in mathematics assessment. Mathematics Teacher, v. 94, n. 1, p. 31-37. 2001.

VAZ, R. F. N; NASSER, L. Um estudo sobre o efeito halo na correção de provas. In: ENCONTRO ESTADUAL DE EDUCAÇÃO MATEMÁTICA DO RIO DE JANEIRO, 7., 2018a, Rio de Janeiro. Anais... Rio de Janeiro: SBEM, 2018a.

VAZ, R. F. N; NASSER, L. Avaliação em matemática: um estudo sobre multicorreção In: SEMINÁRIO INTERNACIONAL DE PESQUISA EM EDUCAÇÃO MATEMÁTICA, 7., 
2018b, Foz do Iguaçu. Anais...Foz do Iguaçu: SBEM, 2018b.

VAZ, R. F. N; NASSER, L. Um estudo de multicorreção com professores de matemática. In: CONFERÊNCIA INTERAMERICANA DE EDUCAÇÃO MATEMÁTICA, 15., 2019, Medelín. Anais...Medelín: CIAEM, 2019.

\section{Biografia Resumida}

Rafael Filipe Novôa Vaz: Licenciatura Plena em Matemática UERJ. Mestre em Ensino de Matemática - PEMAT/UFRJ. Doutorando em Ensino de Matemática - PEMAT/UFRJ, Docente de Matemática - IFRJ/Paracambi, Pesquisador do Projeto Fundão - UFRJ.

Link Lattes: http://lattes.cnpq.br/o867183050486455

Contato: rafael.vaz@ifrj.edu.br

Lilian Nasser: Licenciatura e Bacharelado em Matemática - UFRJ, Mestre em Matemática - UFRJ, Doutora em Educação Matemática - King's College, UniversityofLondon, Pesquisadora do Projeto Fundão - UFRJ, Docente do PEMAT/UFRJ

Contato: lnasser.mat@gmail.com

Link Lattes: http://lattes.cnpq.br/4694849346110414 